\title{
Synthetic lethal interaction of CDK inhibition and autophagy inhibition in human solid cancer cell lines
}

\author{
YOSHINARI OKADA, SHUNSUKE KATO, YASUHIRO SAKAMOTO, \\ TAKAYUKI OISHI and CHIKASHI ISHIOKA
}

\author{
Department of Clinical Oncology, IDAC, Tohoku University, Aoba-ku, Sendai 980-8575, Japan
}

Received September 24, 2016; Accepted March 20, 2017

DOI: 10.3892/or.2017.5684

\begin{abstract}
Cell cycle control is a promising target in cancer treatments, and some small-molecule cyclin-dependent kinase $(\mathrm{CDK})$ inhibitors have exhibited clinical effectiveness. However, no biomarkers predictive of efficacy have been developed. Recent studies have revealed that CDK inhibitor (CKI) proteins, such as p27 and p16, also induced cytoprotective autophagy in cancer cells. However, it is unclear whether small-molecule CKIs also induce autophagy in solid tumors, as induced autophagy promotes cancer cell survival. In this study, we revealed that a CDK4 inhibitor and a CKI with a broad range of targets (flavopiridol) induced autophagy in some, but not all, solid cancer cell lines. Autophagy induction by CDK4 inhibitor was observed in BT474, MDA-MB435S, SKBr3 (derived from breast cancer), A431 (derived from epidermoid cancer), and SW480 (derived from colorectal cancer) cell lines. No such autophagy was observed in MCF7, MDA-MB231 (derived from breast cancer), NCI-N87 (derived from gastric cancer), and KMST-6 (derived from a fibroblast). In the cell lines showing autophagy, which was induced by CDK4 inhibitor, the combination of CDK4 inhibitor and autophagy inhibition by either chloroquine (CQ) or knockdown of ATG5 or BECN1 induced apoptosis. However, it did not induce apoptosis in the cell lines in which autophagy was not induced by CDK4 inhibitor. These findings indicate that the autophagy induced by CDK4 inhibitor mimics stress-induced autophagy in some solid cancer cell lines. The combination of a small-molecule CKI involved
\end{abstract}

Correspondence to: Professor Chikashi Ishioka, Department of Clinical Oncology, IDAC, Tohoku University, 4-1 Seiryo-machi, Aoba-ku, Sendai, Miyagi 980-8575, Japan

E-mail: chikashi@tohoku.ac.jp

Abbreviations: CDK, cyclin-dependent kinase; CKI, CDK inhibitor; $\mathrm{CQ}$, chloroquine; FBS, fetal bovine serum; DMSO, dimethyl sulfoxide; PBS, phosphate-buffered saline; FACS, fluorescenceactivated cell sorting; AIC, autophagy induced by CDK4 inhibitor; HCQ, hydroxychloroquine

Key words: synthetic lethality, cell cycle arrest, CKI, autophagy, apoptosis in $G_{1} / S$ arrest and an autophagy inhibitor leads to a synthetic lethal interaction and could become a new antitumor strategy for solid tumors showing cytoprotective autophagy induced by small-molecule CKIs.

\section{Introduction}

Cell cycle arrest is a key mechanism that is activated by cellular stress, and is strictly controlled by many regulatory mechanisms that either permit or restrain its progression (1). The regulatory factors controlling cell cycle progression are cyclins, cyclindependent kinases (CDKs), CDK inhibitor (CKI) proteins such as p27 and p21, and tumor suppressor gene products p53 and $\mathrm{Rb}$. Abnormalities of the gene structures (mutations, deletions, or amplifications) and the expression levels of their products are frequently observed in various cancers, which result in cell cycle progression and genetic instability (2). Thus, correction of the collapse of cell cycle regulation by small-molecule CKIs in these tumors has offered insight that could potentially lead to effective therapeutic strategies. Flavopiridol, a pan-CDK inhibitor, improved response rates in chronic lymphocytic leukemia (3). Palbociclib, a CDK4 and CDK6 inhibitor, plus fulvestrant prolonged progression-free survival in breast cancer (4). However, no predictable biomarkers of smallmolecule CKIs have been detected.

Recently, CKI proteins involved in $\mathrm{G}_{1} / \mathrm{S}$ arrest have also been shown to induce autophagy (5-7). Autophagy is a catabolic process that occurs via the lysosomal degradation pathway. It is essential for cell survival, differentiation, development, and homeostasis. It not only provides nutrients for maintaining vital cellular functions during starvation but also rids cells of superfluous or damaged organelles, misfolded proteins, and invading microorganisms (8). Autophagy also plays an important role in both tumor progression and tumor suppression (9). Moreover, autophagy is a survival pathway for cancer cells exposed to genotoxic stress and activated oncogenic signals (10). Several lines of evidence have indicated that autophagy could be a novel target for cancer treatment. Inhibition of stress-induced autophagy induces apoptotic cell death; therefore, the combination of autophagy inducible stress and autophagy inhibition may provide a synthetic lethal interaction that could become a rational strategy for cancer treatment (11).

In this study, we examined whether a specific CDK4 inhibitor and a CKI with a broad range of targets (flavopiridol) 
could induce autophagy in human solid cancer and fibroblast cell lines. Moreover, we examined whether inhibition of the autophagy induced by small-molecule CKIs caused apoptosis in these cell lines.

\section{Materials and methods}

Cell lines and culture. The following cell lines were used in this study: BT474; MCF7; MDA-MB231; MDA-MB435S; SKBr3 (derived from breast cancer); A431 (derived from epidermoid cancer); NCI-N87 (derived from gastric cancer); SW480 (derived from colorectal cancer); and KMST-6 (derived from a fibroblast). BT474, MDA-MB231, MDA-MB435S, SKBr3, and NCI-N87 were purchased from American Type Culture Collection. A431 and KMST- 6 were provided by the Institute of Development, Aging, and Cancer, Tohoku University. SW480 was kindly donated by Professor John M. Mariandason, Ludwig Institute for Cancer Research, Austin Hospital. All cell lines were maintained in RPMI-1640 medium (SigmaAldrich, R8758) supplemented with $10 \%$ heat-inactivated fetal bovine serum (FBS) (Gibco, 26140-079) or without FBS (nutrient starvation conditions). The cells were incubated at $37^{\circ} \mathrm{C}$ in a $5 \% \mathrm{CO}_{2}$ humidified atmosphere.

Small-molecule CKIs and autophagy inhibition. CDK4 inhibitor, 2-bromo-12 and 13-dihydro-5 H-indolo-dione [2 and 3 -a] pyrrolo [3 and 4-c] carbazole-5 and 7 (6H)-dione, was purchased from Merck Ltd. (219476-1MG), and flavopiridol was purchased from Santa Cruz Biotechnology, Inc. (sc-202157). Both were dissolved in dimethyl sulfoxide (DMSO) (Wako Pure Chemical Industries Ltd., 043-29355) and added to the cell cultures to make a final concentration of $100 \mathrm{nM}$. CQ was purchased from Tokyo Kasei Kogyo Co., Ltd. (C2301). To inhibit autophagy, CQ was added to the cell cultures to make a final concentration of $50 \mu \mathrm{M}$. ATG5, BECN1, and negative control siRNAs were purchased from Signal Silence, Cell Signaling Technology (\#6345,\#6222, and \#6568). Each siRNA was introduced to the cell cultures to make a final concentration of $100 \mathrm{nM}$ using an X-tremeGENE siRNA transfection reagent (Roche Applied Science Ltd., 4476093).

Western blot analysis. The lysate was subjected to western blot analysis as previously described (12). Cells were harvested and resuspended in lysis buffer containing $50 \mathrm{mM}$ Tris- $\mathrm{HCl}$ (pH 8.0), $150 \mathrm{mM} \mathrm{NaCl}, 5 \mathrm{mM}$ EDTA, and $1 \%$ protease inhibitor cocktail (Sigma-Aldrich, P2714). Anti-sqstm1 (p62) (Santa Cruz Biotechnology, Inc., sc-28359), anti- $\beta$-actin (SigmaAldrich, A5316), anti-atg5, anti-beclin-1, anti-LC3 (Medical \& Biological Laboratories Co., Ltd., PM036), and anti-cleaved caspase-3 (Cell Signaling Technology, \#2630, \#3738, \#9661) antibodies were used.

Immunofluorescence analysis. The strategy for LC3 immunofluorescence was described in a previous study (13). Cells were harvested $18 \mathrm{~h}$ after treatment and fixed with $4 \%$ paraformaldehyde before incubation for $10 \mathrm{~min}$ at room temperature. After washing with Phosphate-buffered saline (PBS) they were permeabilized with $50 \mu \mathrm{g} / \mathrm{ml}$ digitonin (Sigma-Aldrich, D141) for $15 \mathrm{~min}$ at room temperature. After a second wash with PBS, the cells were incubated with anti-LC3 diluted 1:250 for $1 \mathrm{~h}$.
Subsequently, they were washed with PBS and then incubated with anti-rabbit IgG (H + L) FITC (Beckman Coulter, 732745) for $1 \mathrm{~h}$ and visualized using BZ-9000 (Keyence).

Cell cycle analysis by fluorescence-activated cell sorting $(F A C S)$. A total of $1.5 \times 10^{4}$ cells per plate were seeded and incubated in $6-\mathrm{cm}$ culture plates for $24 \mathrm{~h}$. The cells were further incubated in the presence of the relevant compounds for 12-72 h. Subsequently, the cells were collected and FACS analysis was performed as previously described (12).

Cell proliferation analysis. A total of $5 \times 10^{3}$ cells per well were seeded and incubated in a 96-well plate for $24 \mathrm{~h}$. They were then treated with the relevant compounds and further cultured at $37^{\circ} \mathrm{C}$ for $12-72 \mathrm{~h}$. The cell proliferation assays were performed with a Cell Counting Kit-8 (Dojin Laboratories, CK04), as previously described (14).

Statistical analysis. Cell cycle analyses were performed independently in triplicate. The data of cell cycle and cell proliferation analyses are presented as mean \pm standard deviation (SD). In cell cycle analyses, differences between $\mathrm{G}_{1}$ and $S$ phases were analyzed using Student's t-test. All statistical analyses were performed using Microsoft Excel ${ }^{\circledR}$. Significant difference was set at $\mathrm{p}<0.05$.

\section{Results}

Cell cycle arrest and autophagy are induced by nutrient starvation. The aim of this study was to survey the potency of autophagy in eight human solid tumor cell lines, BT474, MDA-MB435S, SKBr3, MCF7, MDA-MB231 (derived from breast cancer), A431 (derived from epidermoid cancer), SW480 (derived from colorectal cancer), and NCI-N87 (derived from gastric cancer), and a human fibroblast, KMST-6. Initially, cell cycle analysis was performed under the condition of nutrient starvation. As shown in Fig. 1A and B, and Table I, the $G_{1}$ phase fraction was increased and the $S$ phase fraction was decreased. However, there was no clear change in the sub $\mathrm{G}_{1}$ phase fraction. Thus, the nutrient starvation induced cell cycle arrest, but not apoptosis, in all of the cell lines.

Next, the induction of autophagy was monitored under the same conditions by measuring the expression level of p62 protein, which is degraded by autophagy. As shown in Fig. 1C, p62 protein was reduced under the nutrient starvation condition in all of the cell lines. Thus, we concluded that the autophagy induced under starvation was associated with cell cycle arrest.

CDK4 inhibitor arrests the cell cycle and induces autophagy in some cell lines. To examine whether CDK4 inhibitor arrested cells at the $G_{1} / S$ phase in the cell cycle and also induced autophagy, cell cycle progression and p62 expression were analyzed. As shown in Fig. 2A and Table II, CDK4 inhibitor arrested cells at the $\mathrm{G}_{1} / \mathrm{S}$ phase in all cell lines, simulating the nutrient starvation condition.

However, under the same condition, p62 degradation was observed only in MDA-MB435S, BT474, SKBr3, A431, and SW480 lines, but not in MCF7, MDA-MB231, NCI-N87, and KMST-6 lines (Fig. 2B). In addition to p62 expression, the 

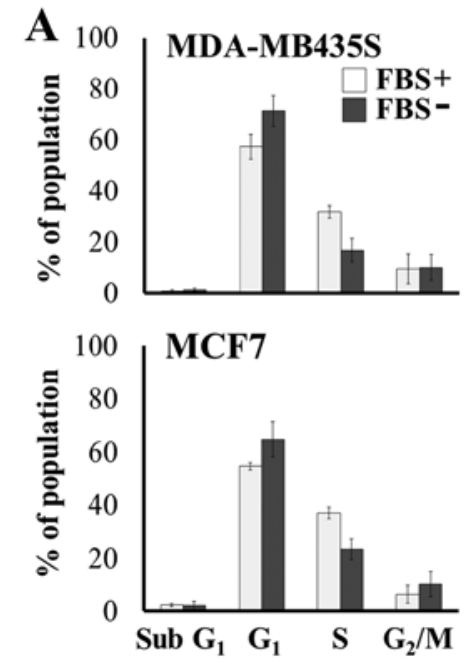

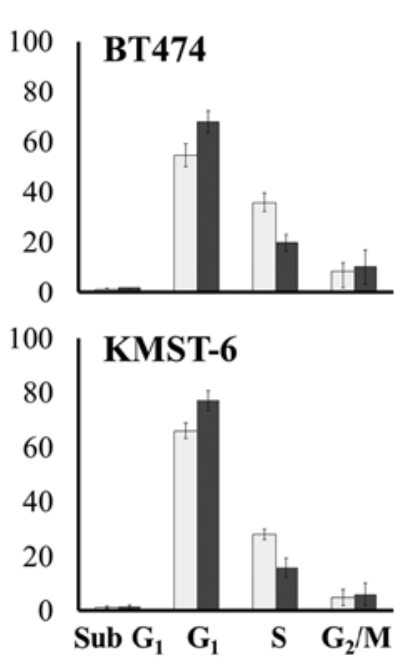

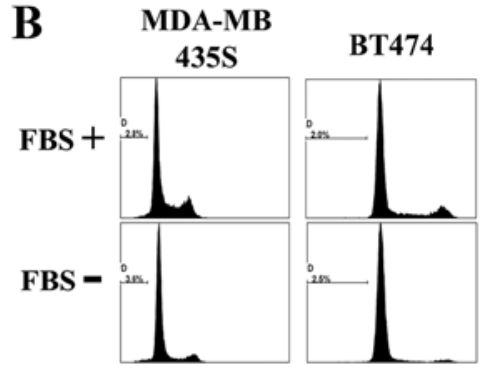

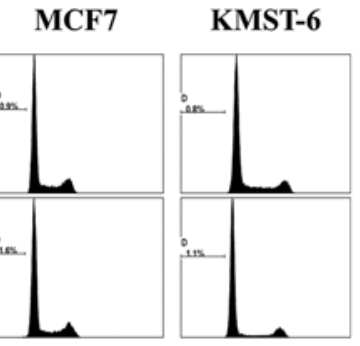

C
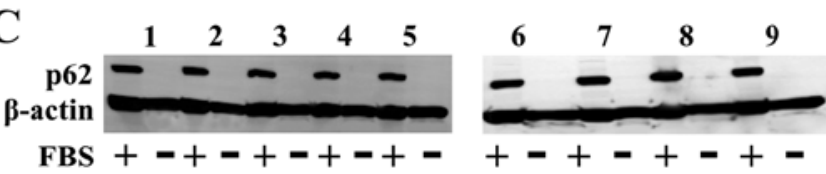

Figure 1. Analysis of the cell cycle and the autophagy induction potency of nutrient starvation. (A) Cell cycle analysis in RPMI medium supplemented with $10 \%$ FBS (normal condition) or no FBS (starvation condition). Each cell line was cultured under normal and starvation conditions for $12 \mathrm{~h}$ at $37^{\circ} \mathrm{C}$ and then cell cycle analysis was performed. The x-axis indicates the phase of the cell cycle. The y-axis indicates the proportion of the cell population. Values shown are mean \pm SD ( $n=3)$. (A) shows the data for the cell lines MDA-MB435S, BT474, MCF7, and KMST-6. Data for the other cell lines are shown in Table I. Differences in $\mathrm{G}_{1}$ and $\mathrm{S}$ phases between normal and starvation conditions were analyzed using t-test. (B) The images of flow cytometry under conditions matching those for (A). (C) Western blot analysis of p62 under normal and starvation conditions as in (A). Lanes: 1, MDA-MB435S; 2, BT474; 3, SKBr3; 4, A431; 5, SW480; 6, MCF7; 7, MDA-MB231; 8, NCI-N87; 9, KMST-6.

Table I. Analysis of the cell cycle of the nutrient starvation.

\begin{tabular}{lrrrrrrr}
\hline Cell line & FBS $(\%)$ & sub- $_{1}(\%)$ & $\mathrm{G}_{1}(\%)$ & $\mathrm{p}$-value & $\mathrm{S}(\%)$ & $\mathrm{p}$-value & $\mathrm{G}_{2} / \mathrm{M}(\%)$ \\
\hline BT474 & 10 & $1.1 \pm 0.4$ & $54.7 \pm 4.7$ & $<0.01$ & $35.6 \pm 3.9$ & 0.03 & $8.6 \pm 3.4$ \\
& 0 & $1.7 \pm 0.1$ & $68.0 \pm 4.3$ & & $19.9 \pm 3.2$ & & $10.4 \pm 6.7$ \\
MDA-MB435S & 10 & $0.9 \pm 0.5$ & $57.5 \pm 4.4$ & 0.01 & $31.8 \pm 1.9$ & 0.02 & $9.8 \pm 5.8$ \\
& 0 & $1.3 \pm 0.5$ & $71.5 \pm 6.1$ & & $17.0 \pm 4.6$ & & $10.2 \pm 4.9$ \\
SKBr3 & 10 & $1.9 \pm 0.3$ & $52.0 \pm 5.9$ & $<0.01$ & $31.9 \pm 2.4$ & 0.01 & $14.2 \pm 4.0$ \\
& 0 & $3.0 \pm 0.8$ & $68.8 \pm 2.7$ & & $13.5 \pm 2.4$ & & $14.7 \pm 4.7$ \\
A431 & 10 & $2.3 \pm 0.6$ & $58.0 \pm 4.9$ & 0.01 & $32.6 \pm 4.6$ & $<0.01$ & $7.1 \pm 3.5$ \\
& 0 & $2.5 \pm 0.7$ & $68.0 \pm 5.0$ & & $20.0 \pm 2.8$ & & $9.5 \pm 3.1$ \\
SW480 & 10 & $1.3 \pm 0.3$ & $63.0 \pm 4.4$ & $<0.01$ & $28.3 \pm 3.8$ & 0.02 & $7.4 \pm 1.7$ \\
& 0 & $1.7 \pm 0.3$ & $70.6 \pm 4.8$ & & $17.1 \pm 3.9$ & & $10.6 \pm 1.3$ \\
MCF7 & 10 & $2.2 \pm 0.6$ & $54.7 \pm 1.4$ & 0.04 & $36.9 \pm 2.1$ & 0.01 & $6.2 \pm 2.9$ \\
& 0 & $2.0 \pm 1.5$ & $64.8 \pm 6.6$ & & $23.3 \pm 3.9$ & & $9.9 \pm 4.2$ \\
MDA-MB231 & 10 & $2.4 \pm 0.7$ & $66.8 \pm 2.4$ & 0.01 & $24.2 \pm 5.8$ & 0.01 & $6.6 \pm 4.1$ \\
& 0 & $4.0 \pm 1.5$ & $78.8 \pm 3.7$ & & $11.0 \pm 2.7$ & & $6.2 \pm 0.5$ \\
NCI-N87 & 10 & $1.6 \pm 0.4$ & $56.4 \pm 5.3$ & $<0.01$ & $33.3 \pm 3.1$ & 0.01 & $8.7 \pm 2.6$ \\
& 0 & $2.2 \pm 0.4$ & $67.0 \pm 4.1$ & & $23.3 \pm 4.8$ & & $7.5 \pm 1.1$ \\
KMST-6 & 10 & $1.2 \pm 0.5$ & $66.0 \pm 4.3$ & 0.01 & $28.0 \pm 1.9$ & 0.03 & $4.8 \pm 2.9$ \\
& 0 & $1.5 \pm 0.6$ & $76.9 \pm 3.6$ & & $15.8 \pm 3.6$ & & $5.8 \pm 4.1$ \\
\hline
\end{tabular}

Data are expressed as mean $\pm \mathrm{SD} . \mathrm{G}_{1}$ and $\mathrm{S}$ fractions were examined paired t-test between FBS $10 \%$ and FBS $0 \%$.

formation of LC3 puncta was also observed in MDA-MB435S and BT474 lines, but not in MCF7 and MDA-MB231 (Fig. 2C). Furthermore, the conversion from LC3-I to LC3-II was also observed in MDA-MB435S, but not in MCF7 (Fig. 2D). These findings indicate that autophagy induced by CDK4 inhibitor does not always occur together with $G_{1} / S$ arrest, which contrasts with events during nutrient starvation.

To determine whether the autophagy is induced in a dosedependent manner, p62 degradation assay was performed using MCF7 and KMST-6, in which autophagy was not induced by 

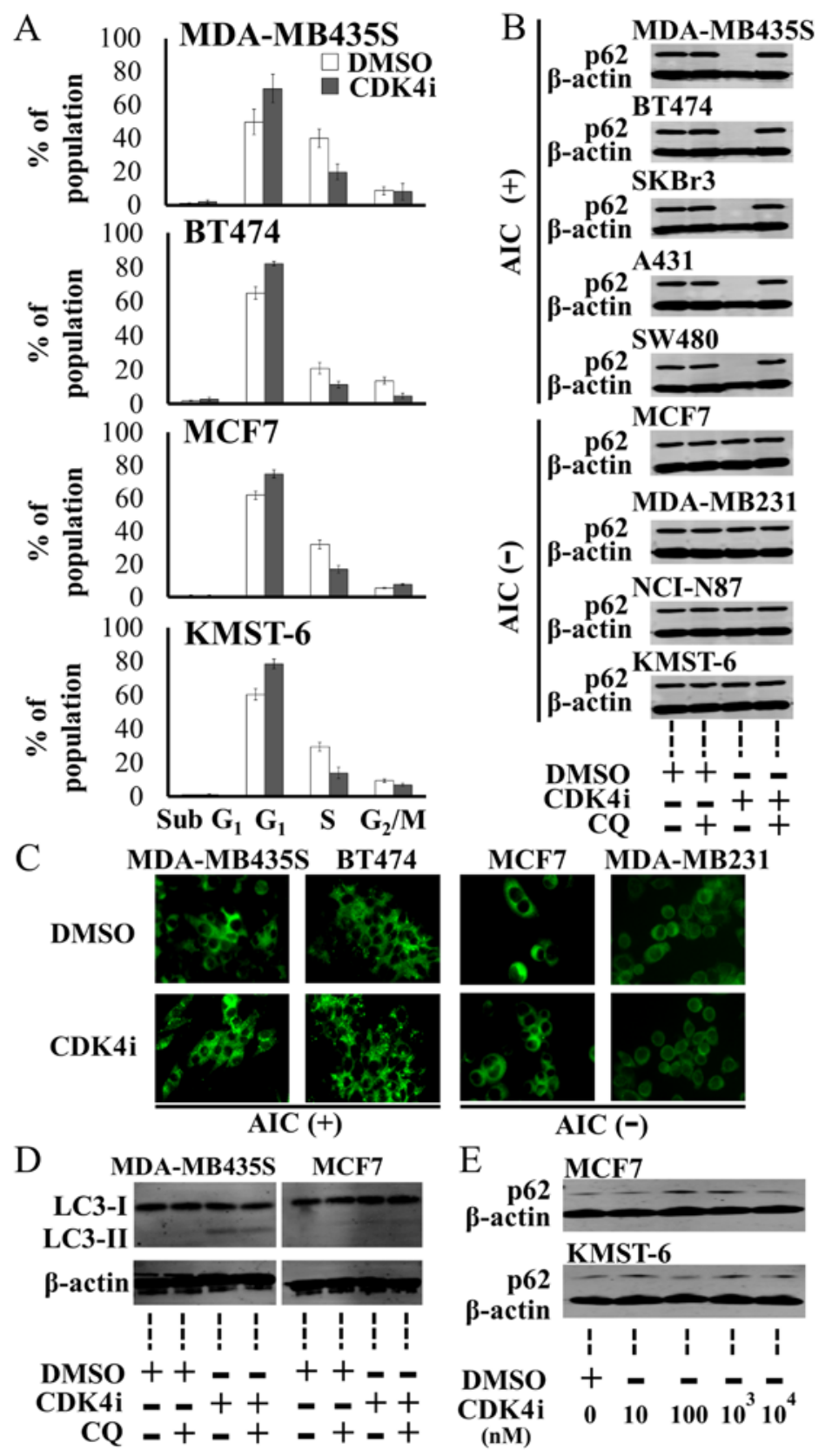

Figure 2. Analysis of the cell cycle and the autophagy induction potency of CDK4 inhibitor. (A) Cell cycle analysis in the presence of CDK4 inhibitor. Each cell line was cultured for $24 \mathrm{~h}$ in the presence of CDK4 inhibitor or DMSO at $37^{\circ} \mathrm{C}$ and then harvested. CDK4 inhibitor and DMSO were administered at a final concentration of $100 \mathrm{nM}$. The $\mathrm{x}$-axis indicates the phase of the cell cycle. The y-axis indicates the proportion of the cell population. Values shown are average \pm SD (n=3). (A) shows the data for the cell lines MDA-MB435S, BT474, MCF7, and KMST-6. Data for the other cell lines are shown in Table II. Differences in the $\mathrm{G}_{1}$ and $\mathrm{S}$ phases between normal and starvation conditions were analyzed using t-test. CDK4i indicates CDK4 inhibitor. (B) Western blot analysis of p62 during treatment with CDK4 inhibitor and/or CQ. Initially, a final concentration of $50 \mu \mathrm{M}$ CQ was administered to the cells. After $48 \mathrm{~h}$, a final concentration of $100 \mathrm{nM} \mathrm{CDK} 4$ inhibitor or DMSO was administered, and the cells were subsequently cultured for a further $24 \mathrm{~h}$ at $37^{\circ} \mathrm{C}$ before collection for western blotting. (C) Using MDA-MB435S, BT474, MCF7, and MDA-MB231, the formation of LC3 puncta was analyzed by immunofluorescence assay. LC3 immunostaining was performed for the cells treated with CDK4 inhibitor, as described for (A). (D) Using MDA-MB435S and MCF7, western blot analysis of LC3 during treatment with CDK4 inhibitor and/or CQ was performed as described for (A). (E) Using AIC (-) cell lines, MCF7 and KMST-6, western blot analysis of $\mathrm{p} 62$ was performed during treatment with CDK4 inhibitor. CDK4 inhibitor or DMSO was administered at a final concentration of $10 \mathrm{nM}, 100 \mathrm{nM}$, $1 \mu \mathrm{M}$, or $10 \mu \mathrm{M}$, and the cells were subsequently cultured for a further $48 \mathrm{~h}$ at $37^{\circ} \mathrm{C}$ before collection for western blotting.

$100 \mathrm{nM}$ CDK4 inhibitor. As a result, p62 degradation was also not observed in both cell lines, despite the presence of $10 \mu \mathrm{M}$ CDK4 inhibitor, which is a sufficient concentration to induce $\mathrm{G}_{1}$ arrest (Fig. 2E).

We termed the autophagy induced by CDK4 inhibitor the AIC or autophagy induced by CDK4 inhibitor. The AIC status of each cell line was as follows: AIC-positive: BT474,
MDA-MB435S, SKBr3, A431, and SW480; AIC-negative: MCF7, MDA-MB231, NCI-N87, and KMST-6.

Induction of apoptosis by CDK4 inhibitor and CQ. p16, an endogenous CKI, has been shown to induce cytoprotective autophagy (7). To examine whether autophagy induced by CDK4 inhibitor was also cytoprotective, we performed an 
Table II. Analysis of the cell cycle of CDK4 inhibitor.

\begin{tabular}{|c|c|c|c|c|c|c|c|}
\hline Cell line & Condition & sub-G $\mathrm{G}_{1}(\%)$ & $\mathrm{G}_{1}(\%)$ & $\mathrm{p}$-value & $\mathrm{S}(\%)$ & $\mathrm{p}$-value & $\mathrm{G}_{2} / \mathrm{M}(\%)$ \\
\hline \multirow[t]{2}{*}{ BT474 } & DMSO & $1.5 \pm 0.4$ & $64.6 \pm 5.0$ & 0.01 & $20.6 \pm 3.3$ & $<0.01$ & $13.3 \pm 2.1$ \\
\hline & CDK4i & $2.6 \pm 1.1$ & $81.9 \pm 1.2$ & & $11.1 \pm 1.8$ & & $4.4 \pm 1.7$ \\
\hline \multirow[t]{2}{*}{ MDA-MB435S } & DMSO & $1.1 \pm 0.3$ & $49.9 \pm 7.6$ & 0.03 & $40.2 \pm 5.5$ & 0.03 & $8.8 \pm 2.4$ \\
\hline & CDK4i & $2.1 \pm 0.9$ & $69.9 \pm 8.7$ & & $19.9 \pm 4.6$ & & $8.1 \pm 5.0$ \\
\hline \multirow[t]{2}{*}{ SKBr3 } & DMSO & $5.0 \pm 1.4$ & $51.6 \pm 4.4$ & $<0.01$ & $36.3 \pm 3.5$ & $<0.01$ & $7.1 \pm 0.5$ \\
\hline & $\mathrm{CDK} 4 \mathrm{i}$ & $3.9 \pm 1.7$ & $59.6 \pm 3.0$ & & $23.6 \pm 1.6$ & & $12.9 \pm 0.3$ \\
\hline \multirow[t]{2}{*}{ A431 } & DMSO & $2.8 \pm 0.7$ & $51.1 \pm 1.9$ & 0.02 & $35.9 \pm 2.6$ & 0.04 & $10.2 \pm 1.4$ \\
\hline & CDK4i & $3.0 \pm 0.7$ & $63.5 \pm 3.2$ & & $26.0 \pm 2.6$ & & $7.5 \pm 1.3$ \\
\hline \multirow[t]{2}{*}{ SW480 } & DMSO & $2.6 \pm 0.6$ & $60.4 \pm 3.6$ & 0.01 & $29.1 \pm 1.9$ & $<0.01$ & $7.9 \pm 2.3$ \\
\hline & $\mathrm{CDK} 4 \mathrm{i}$ & $2.9 \pm 0.9$ & $70.7 \pm 3.4$ & & $18.0 \pm 1.7$ & & $8.5 \pm 2.6$ \\
\hline \multirow[t]{2}{*}{ MCF7 } & DMSO & $0.9 \pm 0.2$ & $61.8 \pm 2.5$ & 0.01 & $31.8 \pm 2.4$ & $<0.01$ & $5.5 \pm 0.3$ \\
\hline & CDK4i & $0.8 \pm 0.2$ & $74.7 \pm 2.5$ & & $16.9 \pm 2.3$ & & $7.6 \pm 0.4$ \\
\hline \multirow[t]{2}{*}{ MDA-MB231 } & DMSO & $1.1 \pm 0.2$ & $63.9 \pm 3.6$ & $<0.01$ & $28.5 \pm 1.7$ & $<0.01$ & $6.5 \pm 2.1$ \\
\hline & $\mathrm{CDK} 4 \mathrm{i}$ & $1.1 \pm 0.4$ & $78.5 \pm 5.5$ & & $15.4 \pm 3.3$ & & $5.1 \pm 2.6$ \\
\hline \multirow[t]{2}{*}{ NCI-N87 } & DMSO & $2.0 \pm 0.6$ & $61.0 \pm 1.3$ & $<0.01$ & $28.8 \pm 2.0$ & $<0.01$ & $8.2 \pm 2.7$ \\
\hline & $\mathrm{CDK} 4 \mathrm{i}$ & $2.3 \pm 0.6$ & $74.6 \pm 2.0$ & & $14.8 \pm 2.4$ & & $8.2 \pm 3.8$ \\
\hline \multirow[t]{2}{*}{ KMST-6 } & DMSO & $0.9 \pm 0.2$ & $60.4 \pm 3.4$ & 0.01 & $29.4 \pm 2.5$ & 0.01 & $9.3 \pm 1.1$ \\
\hline & CDK4i & $0.9 \pm 0.3$ & $78.4 \pm 2.8$ & & $13.9 \pm 3.3$ & & $6.8 \pm 0.8$ \\
\hline
\end{tabular}

Data are expressed as mean $\pm \mathrm{SD} . \mathrm{G}_{1}$ and $\mathrm{S}$ fractions were examined paired $\mathrm{t}$-test between DMSO and CDK4 inhibitor (CDK4i).

Table III. Cell proliferation analysis for the combination of CDK4 inhibitor and CQ.

\begin{tabular}{lrrrr}
\hline Cell line & DMSO & DMSO + CQ & CDK4i & CDK4i + CQ \\
\hline AIC (+) & & & & \\
BT474 & $348 \pm 59$ & $310 \pm 49$ & $150 \pm 39$ & $72 \pm 19$ \\
MDA-MB435S & $286 \pm 86$ & $187 \pm 55$ & $137 \pm 49$ & $71 \pm 27$ \\
SKBr3 & $210 \pm 50$ & $150 \pm 77$ & $111 \pm 39$ & $49 \pm 13$ \\
A431 & $330 \pm 67$ & $288 \pm 48$ & $126 \pm 39$ & $37 \pm 19$ \\
SW480 & $247 \pm 60$ & $219 \pm 43$ & $119 \pm 22$ & $50 \pm 13$ \\
AIC (-) & & & & \\
MCF7 & $329 \pm 58$ & $260 \pm 69$ & $149 \pm 43$ & $98 \pm 19$ \\
MDA-MB231 & $295 \pm 69$ & $210 \pm 58$ & $140 \pm 39$ & $120 \pm 44$ \\
NCI-N87 & $198 \pm 76$ & $80 \pm 44$ & $113 \pm 33$ & $51 \pm 29$ \\
KMST-6 & $238 \pm 40$ & $221 \pm 54$ & $110 \pm 31$ & $120 \pm 54$ \\
\hline
\end{tabular}

Absorbance of $72 \mathrm{~h} /$ absorbance of $0 \mathrm{~h} \times 100 \%$. Data are expressed as mean \pm SD. AIC, autophagy induced by CDK4 inhibitor; CQ, chloroquine; DMSO, dimethyl sulfoxide; CDK4i, CDK4 inhibitor.

analysis of cell proliferation with or without CDK4 inhibitor and/or CQ. CQ is known to be a non-specific autophagy inhibitor. As shown in Fig. 2B, the addition of CQ inhibited p62 degradation by CDK4 inhibitor.
Next, cell proliferation analysis was performed under the same conditions (Fig. 3A). In AIC (+) cell lines (A431 and SW480), the combination of CDK4 inhibitor and CQ inhibited cell proliferation and reduced the number of cells relative to the baseline. In contrast, in AIC (-) cell lines (MCF7 and KMST-6), the combination of these compounds inhibited cell proliferation, but did not reduce the number of cells relative to the baseline. Similar results were also observed in the experiments performed with the other cell lines, excluding NCI-N87 (Table III). To determine the cause of the reduction in the number of cells induced by the combination of CDK4 inhibitor and $\mathrm{CQ}$, cell cycle analysis was performed (Fig. 3B). In AIC (+) cell lines (A431 and SW480), the addition of CQ to CDK4 inhibitor increased the sub- $\mathrm{G}_{1}$ fraction. In contrast, in AIC (-) cell lines (MCF7 and KMST-6), the addition of CQ did not change the sub- $\mathrm{G}_{1}$ fraction. Similar results were also observed in the experiments performed with the other cell lines (Table IV). These findings indicated that CDK4 inhibitor in combination with $\mathrm{CQ}$ induced apoptosis and promoted a synthetic lethal interaction in AIC (+) cell lines, suggesting that the autophagy induced by CDK4 inhibitor may be cytoprotective in these cell lines.

Induction of apoptosis by CDK4 inhibitor and ATG5 or BECN1 knockdown. To determine whether the induction of apoptosis by the combination of CDK4 inhibitor and CQ was due to the inhibition of autophagy by $\mathrm{CQ}$, we analyzed cell proliferation and cell cycle progression with ATG5 and BECN1 

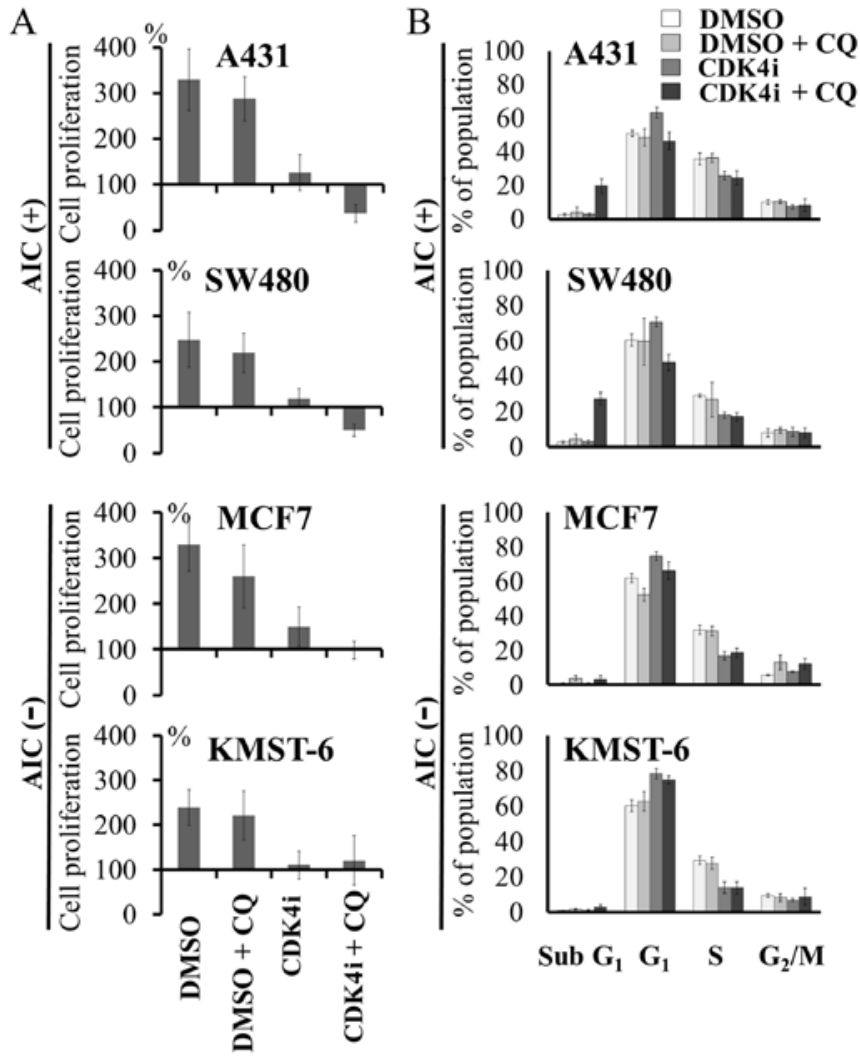

Figure 3. Cell proliferation and cell cycle analysis for the combination of CDK4 inhibitor and CQ. (A) After treatment with CDK4 inhibitor and/or CQ as shown in Fig. 2B, cell proliferation analysis was performed. Cell viability just before treatment with CQ was $100 \%$, and the vertical axis corresponds to the absorbance ratio. The $\mathrm{x}$-axis indicates the kind of treatment. The $\mathrm{y}$-axis indicates the proportion of cell proliferation. Values shown are mean $\pm S D(n=3)$. (A) shows the data for the cell lines A431, SW480, MCF7, and KMST-6. Data for the other cell lines are shown in Table III. (B) After treatment with CDK4 inhibitor and/ or $\mathrm{CQ}$ as described for Fig. 2B, cell cycle analysis was performed. The $\mathrm{x}$-axis indicates the phase of the cell cycle. The $y$-axis indicates the proportion of the cell population. Values shown are mean $\pm \mathrm{SD}(\mathrm{n}=3)$. (B) shows the data for the cell lines A431, SW480, MCF7, and KMST-6. Data for the other cell lines are shown in Table IV. Differences in sub-G $\mathrm{G}_{1}$ phase between DMSO + CQ and CDK4 inhibitor + CQ were analyzed using t-test. CDK4i, CDK4 inhibitor.

siRNA instead of CQ. Atg5 is an E3 ubiquitin ligase which forms a complex with Atg12 and Atg16L1, and this complex is necessary in autophagosome elongation. Beclin-1 interacts with either BCL-2 or the phosphatidylinositol 3 kinase, and shows to be involved in autophagy induction. Both the proteins play critical roles in the regulation of autophagy. As shown in Fig. 4A, siRNA of ATG5 and BECN1 suppressed the expression of Atg5 and Beclin-1 proteins, respectively, and also inhibited p62 degradation induced by CDK4 inhibitor in AIC (+) cell lines, which is the same as observed with CQ (Fig. 4B). In AIC (-) cell lines, p62 was not downregulated by CDK4 inhibitor, and $A T G 5$ and BECN1 siRNA did not influence p62 protein levels. Next, we examined the expression levels of Atg5 and Beclin-1 by CDK4 inhibitor and CQ. As shown in Fig. 4C, CDK4 inhibitor increased the expression of Atg5 and Beclin-1 proteins in AIC (+) cell lines, but not in AIC (-) cell lines. These results indicated that CDK4 inhibitor induced autophagy via Atg5 and Beclin-1. As shown in Fig. 4D, CQ did not change the expression of Atg5 and Beclin-1 proteins in either AIC (+) or AIC (-) cell lines.

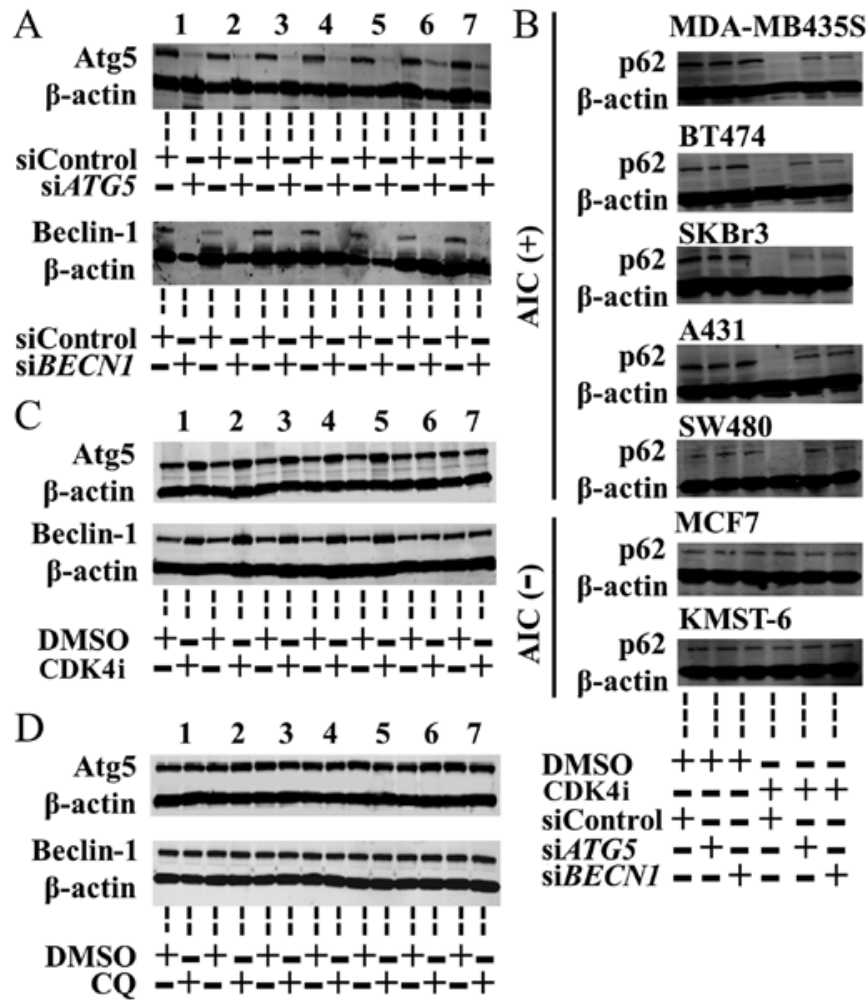

Figure 4. Analysis of the autophagy inhibition potency of ATG5 or BECN1 knockdown. (A) The knockdown efficacy of Atg5 and Beclin-1 using siRNA was determined. Using MDA-MB435S, BT474, SKBr3, A431, SW480, MCF7, and KMST-6, a western blot was performed $48 \mathrm{~h}$ after siRNA transfection. 1, MDA-MB435S; 2, BT474; 3, SKBr3; 4, A431; 5, SW480; 6, MCF7; 7, KMST-6. (B) Using the same cell lines as in (A), western blot analysis of p62 was performed following transfection with ATG5, BECN1, or negative control siRNA with and without CDK4 inhibitor. Following a 48-h siRNA transfection period, CDK4 inhibitor or DMSO at a final concentration of $100 \mathrm{nM}$ was administered to the cells and they were cultured for $24 \mathrm{~h}$ at $37^{\circ} \mathrm{C}$ before collection for western blotting. (C) Using the same cell lines as in (A), western blot analysis of Atg5 and Beclin-1 was performed after treatment with CDK4 inhibitor. A final concentration of $100 \mathrm{nM} \mathrm{CDK} 4$ inhibitor or DMSO was administered to the cells, and these were cultured for $24 \mathrm{~h}$ at $37^{\circ} \mathrm{C}$ before collection for western blotting. 1, MDA-MB435S; 2, BT474; 3 , SKBr3; 4, A431; 5, SW480; 6, MCF7; 7, KMST-6. (D) Using the same cell lines as in (A), western blot analysis of Atg5 and Beclin-1 was performed after treatment with CQ. A final concentration of $50 \mu \mathrm{M}$ CQ or DMSO was administered to the cells, and these were cultured for $24 \mathrm{~h}$ at $37^{\circ} \mathrm{C}$ before collection for western blotting. Lanes: 1, MDA-MB435S; 2, BT474; 3, SKBr3; 4, A431; 5, SW480; 6, MCF7; 7, KMST-6. CDK4i, CDK4 inhibitor.

In terms of cell proliferation, a remarkable reduction in the number of cells was observed when CDK4 inhibitor was combined with the knockdown of ATG5 or BECN1 in AIC (+) cell lines, but not in AIC (-) cell lines (Fig. 5A, Table V). In cell cycle analysis, the combination of CDK4 inhibitor and knockdown of $A T G 5$ or $B E C N 1$ resulted in an increase in the sub- $\mathrm{G}_{1}$ fraction in AIC (+) cell lines, but not in AIC (-) cell lines (Fig. 5B and C, Table VI). These findings indicated that the cytotoxic effect of CQ in AIC (+) cell lines was due to the autophagy inhibition by $\mathrm{CQ}$.

Confirmation of apoptosis induced by the combination of CDK4 inhibitor and autophagy inhibition. To confirm that the reduction in the number of cells observed when CDK4 inhibitor was combined with autophagy inhibition was due to apoptosis, the production of cleaved caspase-3 was measured. 
Table IV. Cell cycle analysis for the combination of CDK4 inhibitor and CQ.

\begin{tabular}{|c|c|c|c|c|c|c|}
\hline Cell line & Condition & sub- $\mathrm{G}_{1}(\%)$ & p-value & $\mathrm{G}_{1}(\%)$ & $\mathrm{S}(\%)$ & $\mathrm{G}_{2} / \mathrm{M}(\%)$ \\
\hline \multicolumn{7}{|l|}{$\mathrm{AIC}(+)$} \\
\hline BT474 & $\begin{array}{l}\mathrm{DMSO}+\mathrm{CQ} \\
\mathrm{CDK} 4 \mathrm{i}+\mathrm{CQ}\end{array}$ & $\begin{array}{r}2.6 \pm 0.8 \\
28.9 \pm 2.9\end{array}$ & $<0.01$ & $\begin{array}{l}68.4 \pm 3.7 \\
55.8 \pm 5.1\end{array}$ & $\begin{array}{c}20.2 \pm 4.4 \\
8.9 \pm 0.7\end{array}$ & $\begin{array}{l}8.8 \pm 1.5 \\
6.4 \pm 2.9\end{array}$ \\
\hline MDA-MB435S & $\begin{array}{l}\mathrm{DMSO}+\mathrm{CQ} \\
\mathrm{CDK} 4 \mathrm{i}+\mathrm{CQ}\end{array}$ & $\begin{array}{r}4.0 \pm 1.6 \\
16.6 \pm 3.5\end{array}$ & $<0.01$ & $\begin{array}{l}56.4 \pm 2.9 \\
51.0 \pm 1.5\end{array}$ & $\begin{array}{l}33.6 \pm 4.0 \\
23.7 \pm 1.3\end{array}$ & $\begin{array}{l}6.0 \pm 2.7 \\
8.7 \pm 3.7\end{array}$ \\
\hline SKBr3 & $\begin{array}{l}\mathrm{DMSO}+\mathrm{CQ} \\
\mathrm{CDK} 4 \mathrm{i}+\mathrm{CQ}\end{array}$ & $\begin{array}{r}7.6 \pm 1.7 \\
23.7 \pm 3.9\end{array}$ & 0.02 & $\begin{array}{l}49.3 \pm 5.1 \\
40.7 \pm 5.0\end{array}$ & $\begin{array}{l}35.3 \pm 4.6 \\
24.4 \pm 1.1\end{array}$ & $\begin{array}{r}7.8 \pm 2.2 \\
11.2 \pm 2.1\end{array}$ \\
\hline A431 & $\begin{array}{l}\mathrm{DMSO}+\mathrm{CQ} \\
\mathrm{CDK} 4 \mathrm{i}+\mathrm{CQ}\end{array}$ & $\begin{array}{r}4.1 \pm 3.2 \\
19.9 \pm 4.4\end{array}$ & 0.03 & $\begin{array}{l}48.8 \pm 5.2 \\
46.6 \pm 5.3\end{array}$ & $\begin{array}{l}36.6 \pm 2.9 \\
24.9 \pm 4.2\end{array}$ & $\begin{array}{r}10.5 \pm 0.9 \\
8.6 \pm 3.3\end{array}$ \\
\hline SW480 & $\begin{array}{l}\mathrm{DMSO}+\mathrm{CQ} \\
\mathrm{CDK} 4 \mathrm{i}+\mathrm{CQ}\end{array}$ & $\begin{array}{r}4.3 \pm 2.5 \\
27.2 \pm 3.5\end{array}$ & 0.01 & $\begin{array}{l}59.5 \pm 9.1 \\
47.8 \pm 4.6\end{array}$ & $\begin{array}{l}26.8 \pm 9.9 \\
17.0 \pm 1.7\end{array}$ & $\begin{array}{l}9.4 \pm 1.7 \\
8.0 \pm 2.8\end{array}$ \\
\hline \multicolumn{7}{|l|}{ AIC (-) } \\
\hline MCF7 & $\begin{array}{l}\mathrm{DMSO}+\mathrm{CQ} \\
\mathrm{CDK} 4 \mathrm{i}+\mathrm{CQ}\end{array}$ & $\begin{array}{l}3.8 \pm 1.4 \\
3.2 \pm 1.2\end{array}$ & 0.15 & $\begin{array}{l}52.2 \pm 3.7 \\
66.2 \pm 4.7\end{array}$ & $\begin{array}{l}30.9 \pm 2.8 \\
18.5 \pm 2.6\end{array}$ & $\begin{array}{l}13.1 \pm 4.2 \\
12.1 \pm 3.3\end{array}$ \\
\hline MDA-MB231 & $\begin{array}{l}\mathrm{DMSO}+\mathrm{CQ} \\
\mathrm{CDK} 4 \mathrm{i}+\mathrm{CQ}\end{array}$ & $\begin{array}{l}1.7 \pm 0.6 \\
1.9 \pm 0.2\end{array}$ & 0.28 & $\begin{array}{l}62.6 \pm 3.9 \\
77.2 \pm 3.8\end{array}$ & $\begin{array}{l}29.9 \pm 3.2 \\
15.7 \pm 3.8\end{array}$ & $\begin{array}{l}5.8 \pm 1.5 \\
5.2 \pm 0.2\end{array}$ \\
\hline NCI-N87 & $\begin{array}{l}\mathrm{DMSO}+\mathrm{CQ} \\
\mathrm{CDK} 4 \mathrm{i}+\mathrm{CQ}\end{array}$ & $\begin{array}{l}2.3 \pm 0.9 \\
2.4 \pm 0.7\end{array}$ & 0.45 & $\begin{array}{l}60.7 \pm 5.2 \\
75.7 \pm 3.1\end{array}$ & $\begin{array}{l}29.0 \pm 2.9 \\
14.0 \pm 2.2\end{array}$ & $\begin{array}{l}8.0 \pm 3.2 \\
7.9 \pm 1.6\end{array}$ \\
\hline KMST-6 & $\begin{array}{l}\mathrm{DMSO}+\mathrm{CQ} \\
\mathrm{CDK} 4 \mathrm{i}+\mathrm{CQ}\end{array}$ & $\begin{array}{l}1.6 \pm 0.3 \\
3.0 \pm 1.2\end{array}$ & 0.09 & $\begin{array}{l}62.6 \pm 5.5 \\
74.7 \pm 2.4\end{array}$ & $\begin{array}{l}27.6 \pm 3.5 \\
13.6 \pm 3.5\end{array}$ & $\begin{array}{l}8.2 \pm 2.3 \\
8.7 \pm 4.7\end{array}$ \\
\hline
\end{tabular}

Data are expressed as mean $\pm \mathrm{SD}$. sub- $\mathrm{G}_{1}$ fraction was examined paired t-test between DMSO + CQ and CDK4 inhibitor (CDK4i) + CQ. AIC, autophagy induced by CDK4 inhibitor.

Table V. Cell proliferation analysis for the combination of CDK4 inhibitor and ATG5 or BECN1 knockdown.

\begin{tabular}{|c|c|c|c|c|c|c|}
\hline Cell line & $\begin{array}{l}\mathrm{DMSO}+ \\
\text { siControl }\end{array}$ & $\begin{array}{c}\mathrm{DMSO}+ \\
\text { siATG5 }\end{array}$ & $\begin{array}{l}\mathrm{DMSO}+ \\
\text { siBECN1}\end{array}$ & $\begin{array}{l}\text { CDK4i + } \\
\text { siControl }\end{array}$ & $\begin{array}{c}\mathrm{CDK} 4 \mathrm{i}+ \\
\mathrm{si} A T G 5\end{array}$ & $\begin{array}{l}\text { CDK4i + } \\
\text { siBECN1 }\end{array}$ \\
\hline \multicolumn{7}{|l|}{$\mathrm{AIC}(+)$} \\
\hline BT474 & $247 \pm 52$ & $194 \pm 45$ & $155 \pm 74$ & $116 \pm 15$ & $67 \pm 2$ & $64 \pm 9$ \\
\hline MDA-MB435S & $208 \pm 10$ & $123 \pm 14$ & $116 \pm 22$ & $108 \pm 23$ & $55 \pm 22$ & $49 \pm 14$ \\
\hline SKBr3 & $171 \pm 25$ & $129 \pm 21$ & $116 \pm 25$ & $118 \pm 14$ & $62 \pm 16$ & $65 \pm 19$ \\
\hline A431 & $248 \pm 39$ & $225 \pm 31$ & $205 \pm 16$ & $128 \pm 7$ & $67 \pm 4$ & $76 \pm 39$ \\
\hline SW480 & $264 \pm 55$ & $222 \pm 42$ & $219 \pm 13$ & $123 \pm 15$ & $51 \pm 9$ & $60 \pm 16$ \\
\hline \multicolumn{7}{|l|}{$\operatorname{AIC~(-)~}$} \\
\hline MCF7 & $224 \pm 5$ & $196 \pm 46$ & $191 \pm 5$ & $133 \pm 26$ & $141 \pm 26$ & $125 \pm 13$ \\
\hline KMST-6 & $210 \pm 28$ & $189 \pm 15$ & $194 \pm 29$ & $130 \pm 13$ & $137 \pm 15$ & $122 \pm 12$ \\
\hline
\end{tabular}

Absorbance of $72 \mathrm{~h}$ /absorbance of $0 \mathrm{~h}$ x 100\%. Data are expressed as mean \pm SD. AIC, autophagy induced by CDK4 inhibitor; DMSO, dimethyl sulfoxide; CDK4i, CDK4 inhibitor.

Cleaved caspase-3 was produced when CDK4 inhibitor was combined with autophagy inhibition, by CQ as well as by $A T G 5$ or BECN1 knockdown (Fig. 6).

Induction of apoptosis by the combination of flavopiridol and autophagy inhibition. The aim of this experiment was to determine whether flavopiridol, a small molecule CKI with a broad range of targets, also induced apoptosis in AIC (+) cell lines when the cells were subjected to autophagy inhibition. As shown in Fig. 7A, the addition of flavopiridol to MDA-MB435S cells resulted in p62 degradation. The combination of flavopiridol and autophagy inhibition by either CQ 

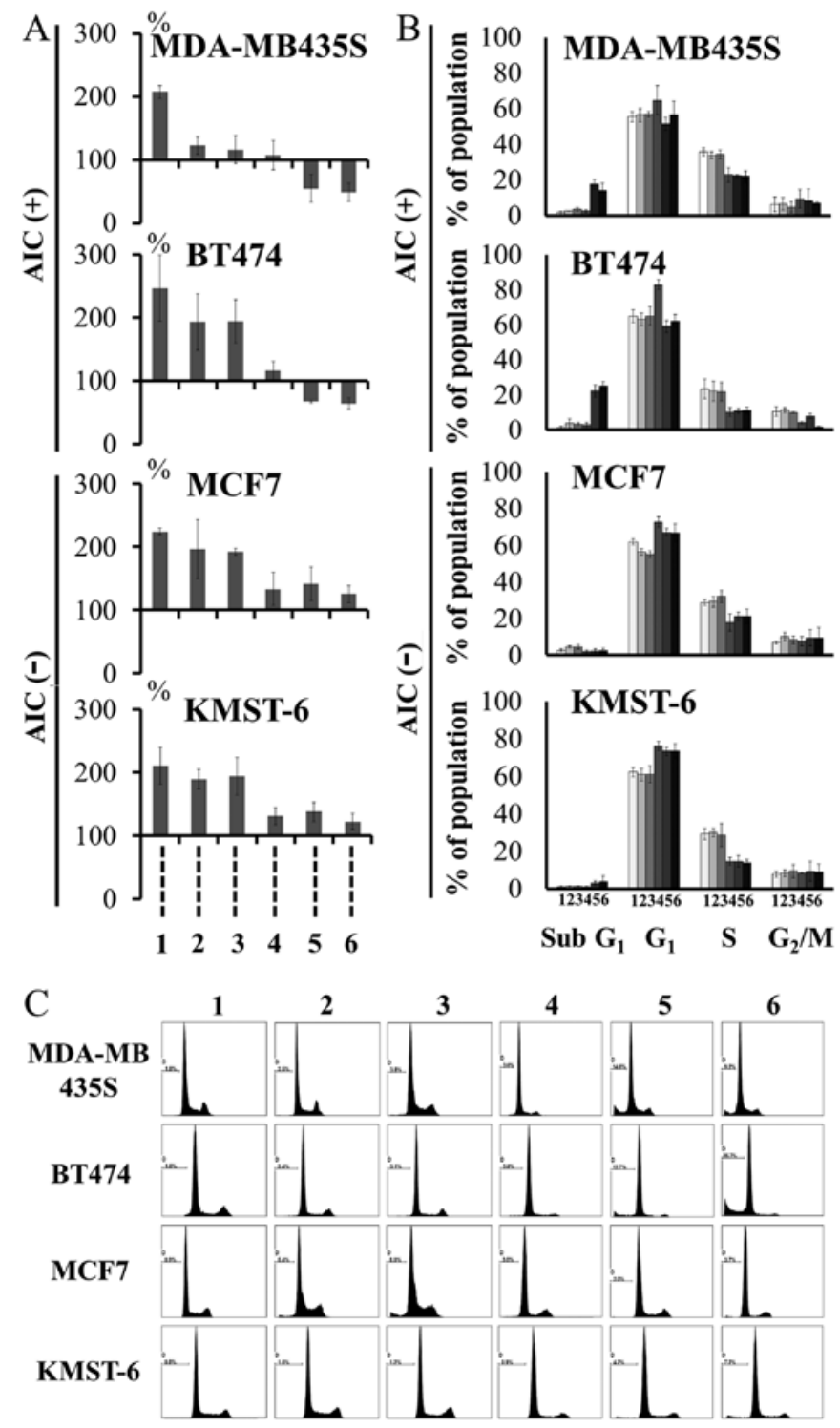

Figure 5. Cell proliferation and cell cycle analysis for the combination of CDK4 inhibitor and $A T G 5$ or $B E C N 1$ knockdown. (A) Cell proliferation analysis under the conditions as described for Fig. 4B. Cell viability just before treatment with siRNA was $100 \%$, and the vertical axis corresponds to the absorbance ratio. The $\mathrm{x}$-axis indicates the type of treatment. The $\mathrm{y}$-axis indicates the proportion of cell proliferation. Values shown are mean $\pm \mathrm{SD}(\mathrm{n}=3)$. (A) shows the data for the cell lines MDA-MB435S, BT474, MCF7, and KMST-6. Data for the other cell lines are shown in Table V. 1, DMSO + siControl; 2, DMSO + siATG5; 3, DMSO + siBECN1; 4, CDK4i + siControl; 5, CDK4i + siATG5; 6,

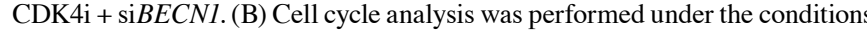
as described for (A). The $\mathrm{x}$-axis indicates the phase of the cell cycle. The y-axis indicates the proportion of the cell population. Values shown are mean $\pm \mathrm{SD}$ $(n=3)$. (B) shows the data for the cell lines MDA-MB435S, BT474, MCF7, and KMST-6. Data for the other cell lines are shown in Table VI. Differences in sub- $\mathrm{G}_{1}$ phase between DMSO + siControl and CDK4 inhibitor + siControl, between DMSO + siATG5 and CDK4 inhibitor + siATG5, and between DMSO $+\mathrm{si} B E C N 1$ and CDK4 inhibitor $+\mathrm{si} B E C N 1$ were analyzed using t-test. Lanes: 1, DMSO + siControl; 2, DMSO + siATG5; 3, DMSO + siBECN1; 4, CDK4 + siControl; $5, \mathrm{CDK} 4 \mathrm{i}+\mathrm{si} A T G 5 ; 6, \mathrm{CDK} 4 \mathrm{i}+\mathrm{siBECN1}$. (C) Images of flow cytometry under the conditions as shown in (B). Lanes: 1, DMSO + siControl; 2, DMSO + siATG5; 3, DMSO + siBECN1; 4, CDK4i + siControl; 5, CDK4i + siATG5; 6, CDK4i + siBECN1. CDK4i, CDK4 inhibitor.

or knockdown of ATG5 or BECN1 resulted in an increase in the sub- $\mathrm{G}_{1}$ fraction (Fig. 7B and C). Thus, flavopiridol, like CDK4 inhibitor, induced cytoprotective autophagy in the AIC (+) MDA-MB435S cell line.
MDA-MB435S

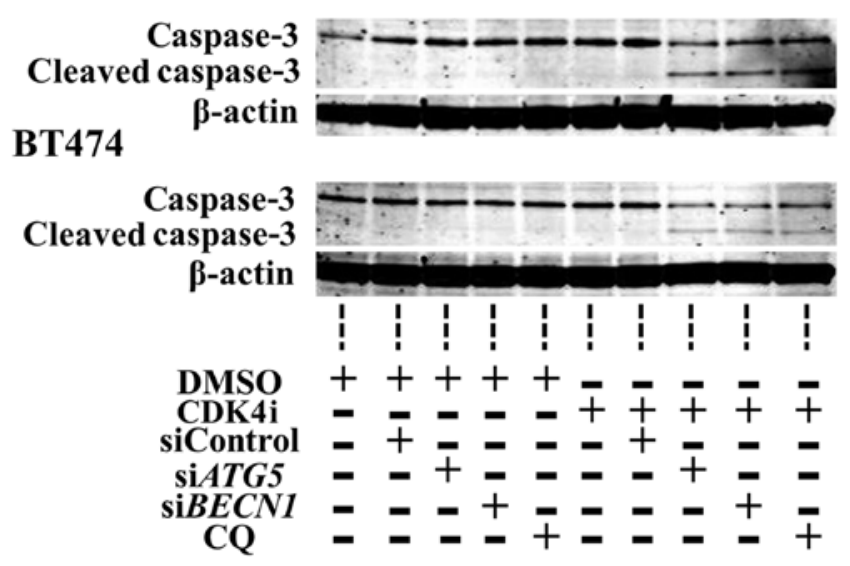

Figure 6. Apoptosis analysis for the combination of CDK4 inhibitor and autophagy inhibition by cleaved caspase-3 assay. Using AIC (+) cell lines, MDA-MB435S and BT474, a cleaved caspase-3 assay was performed under the conditions as described in Figs. 2B and 5B. CDK4i, CDK4 inhibitor.

\section{Discussion}

The cell cycle progression of cells deprived of an essential nutrient or growth factor (starvation) or damaged by ionizing radiation or a DNA-damaging agent (genotoxic stress) is blocked at the $\mathrm{G}_{1} / \mathrm{S}$ transition, especially at a point in mid- $G_{1}(15)$. This point is called the restriction point (R point) and is the point at which the cell becomes 'committed' to the cell cycle because, after this point, extracellular proliferation stimulants are no longer required. In contrast, the cell cycle progression of $G_{1}$ cells that have not reached the $R$ point is immediately arrested. Both starvation and genotoxic stress induce autophagy to maintain homeostasis for survival (8). Recent research has shown that the expression or activation of CKIs involved in $\mathrm{G}_{1} / \mathrm{S}$ arrest, such as p27, p21, and p16, also induces autophagy (5-7). Thus, we hypothesized that cell cycle arrest at the $\mathrm{G}_{1} / \mathrm{S}$ phase was required to induce autophagy and that this was achieved by small-molecule CKIs. In our study, starvation stress resulted in cell cycle arrest at the $\mathrm{G}_{1} / \mathrm{S}$ phase and autophagy in all of the cell lines that we examined. However, small-molecule CKIs only have the ability to induce autophagy in some cell lines [AIC (+) cell lines]. It has become clear that autophagy is not necessarily induced by small-molecule CKIs in all solid cancer cells. Furthermore, in KMST-6, a cell line derived from a human fibroblast, autophagy was not induced by CDK4 inhibitor. These results indicate that autophagy induction by CDK4 inhibitor is only a feature of some types of cancer cells. In AIC (-) cell lines, autophagy could be induced by starvation stress but not by CDK4 inhibitors at a dosage sufficiently high to induce cell cycle arrest at the $\mathrm{G}_{1} / \mathrm{S}$ phase. Therefore, we speculate that cell cycle arrest at the $\mathrm{G}_{1} / \mathrm{S}$ phase is necessary but not sufficient for the induction of autophagy.

Several studies have indicated that autophagy promotes cancer cell survival after chemotherapy, radiation therapy, or endocrine therapy (16-18). In our study, autophagy inhibition with small-molecule CKIs promoted cell death in AIC (+) cell lines, but not in AIC (-) cell lines, excluding NCI-N87. In NCI-N87, CQ without CDK4 inhibitor reduced the number of 
Table VI. Cell cycle analysis for the combination of CDK4 inhibitor and ATG5 and BECN1 knockdown.

\begin{tabular}{|c|c|c|c|c|c|c|}
\hline Cell line & Condition & sub- $\mathrm{G}_{1}(\%)$ & p-value & $\mathrm{G}_{1}(\%)$ & $\mathrm{S}(\%)$ & $\mathrm{G}_{2} / \mathrm{M}(\%)$ \\
\hline \multicolumn{7}{|l|}{$\mathrm{AIC}(+)$} \\
\hline \multirow[t]{6}{*}{ BT474 } & DMSO + siControl & $1.4 \pm 0.6$ & - & $64.9 \pm 3.5$ & $23.3 \pm 5.6$ & $10.4 \pm 2.7$ \\
\hline & DMSO + siATG5 & $3.9 \pm 2.4$ & - & $62.9 \pm 4.6$ & $21.9 \pm 5.8$ & $11.3 \pm 1.2$ \\
\hline & $\mathrm{DMSO}+\mathrm{si} B E C N 1$ & $3.3 \pm 0.8$ & - & $65.0 \pm 6.0$ & $21.8 \pm 5.4$ & $9.9 \pm 0.2$ \\
\hline & CDK4i + siControl & $2.9 \pm 1.2$ & 0.09 & $82.9 \pm 2.9$ & $10.1 \pm 2.4$ & $4.1 \pm 0.7$ \\
\hline & CDK4i + siATG5 & $22.2 \pm 3.5$ & $<0.01$ & $59.0 \pm 3.6$ & $10.9 \pm 1.5$ & $7.9 \pm 1.4$ \\
\hline & $\mathrm{CDK} 4 \mathrm{i}+\mathrm{si} B E C N 1$ & $25.1 \pm 2.4$ & $<0.01$ & $62.1 \pm 3.8$ & $11.2 \pm 1.8$ & $1.6 \pm 0.4$ \\
\hline \multirow[t]{6}{*}{ MDA-MB435S } & DMSO + siControl & $2.0 \pm 0.6$ & - & $55.6 \pm 2.7$ & $35.9 \pm 2.1$ & $6.5 \pm 4.2$ \\
\hline & DMSO + siATG5 & $2.7 \pm 0.2$ & - & $56.6 \pm 5.4$ & $34.0 \pm 2.0$ & $6.7 \pm 3.6$ \\
\hline & $\mathrm{DMSO}+\mathrm{si} B E C N 1$ & $3.7 \pm 1.0$ & - & $56.9 \pm 1.5$ & $34.5 \pm 2.4$ & $4.9 \pm 2.9$ \\
\hline & CDK4i + siControl & $2.7 \pm 0.8$ & 0.13 & $64.9 \pm 8.4$ & $23.0 \pm 4.0$ & $9.4 \pm 5.2$ \\
\hline & CDK4i + siATG5 & $17.7 \pm 2.7$ & $<0.01$ & $51.5 \pm 3.6$ & $22.5 \pm 0.6$ & $8.3 \pm 5.7$ \\
\hline & $\mathrm{CDK} 4 \mathrm{i}+\mathrm{si} B E C N 1$ & $14.2 \pm 5.1$ & 0.03 & $56.7 \pm 7.6$ & $22.1 \pm 3.3$ & $7.0 \pm 0.8$ \\
\hline \multirow[t]{6}{*}{ SKBr3 } & DMSO + siControl & $6.3 \pm 1.1$ & - & $52.8 \pm 3.5$ & $31.3 \pm 2.8$ & $9.6 \pm 5.2$ \\
\hline & DMSO + siATG5 & $6.6 \pm 1.0$ & - & $51.8 \pm 8.3$ & $34.3 \pm 4.5$ & $7.3 \pm 4.8$ \\
\hline & $\mathrm{DMSO}+\mathrm{si} B E C N 1$ & $5.7 \pm 1.1$ & - & $53.6 \pm 3.9$ & $32.0 \pm 2.6$ & $8.7 \pm 2.4$ \\
\hline & CDK4i + siControl & $3.9 \pm 2.0$ & 0.09 & $58.9 \pm 3.1$ & $23.7 \pm 2.0$ & $13.5 \pm 0.9$ \\
\hline & CDK4i + siATG5 & $21.1 \pm 4.4$ & $<0.01$ & $40.7 \pm 1.8$ & $24.7 \pm 4.7$ & $13.4 \pm 1.8$ \\
\hline & CDK4i + siBECN1 & $19.0 \pm 6.6$ & 0.04 & $42.2 \pm 3.4$ & $23.9 \pm 4.8$ & $14.9 \pm 1.6$ \\
\hline \multirow[t]{6}{*}{ A431 } & DMSO + siControl & $3.5 \pm 0.9$ & - & $52.0 \pm 4.5$ & $34.1 \pm 3.8$ & $10.4 \pm 0.2$ \\
\hline & DMSO + siATG5 & $4.3 \pm 0.5$ & - & $48.4 \pm 3.6$ & $36.5 \pm 2.9$ & $10.8 \pm 1.2$ \\
\hline & $\mathrm{DMSO}+\mathrm{si} B E C N 1$ & $3.1 \pm 1.9$ & - & $50.2 \pm 4.2$ & $35.7 \pm 3.0$ & $11.0 \pm 3.1$ \\
\hline & CDK4i + siControl & $3.6 \pm 0.3$ & 0.42 & $62.6 \pm 2.5$ & $24.7 \pm 2.4$ & $9.1 \pm 0.4$ \\
\hline & CDK4i + siATG5 & $16.8 \pm 6.9$ & 0.04 & $52.4 \pm 6.2$ & $22.1 \pm 2.8$ & $8.7 \pm 2.1$ \\
\hline & CDK4i + si BECN 1 & $18.3 \pm 4.2$ & $<0.01$ & $49.6 \pm 3.1$ & $25.7 \pm 2.2$ & $6.3 \pm 0.9$ \\
\hline \multirow[t]{6}{*}{ SW480 } & DMSO + siControl & $2.7 \pm 0.4$ & - & $61.7 \pm 3.9$ & $27.3 \pm 2.7$ & $8.3 \pm 1.6$ \\
\hline & DMSO + siATG5 & $3.7 \pm 2.5$ & - & $58.9 \pm 4.0$ & $28.9 \pm 3.3$ & $8.5 \pm 1.8$ \\
\hline & $\mathrm{DMSO}+\mathrm{si} B E C N 1$ & $2.8 \pm 0.9$ & - & $63.1 \pm 3.6$ & $26.5 \pm 4.1$ & $7.6 \pm 1.4$ \\
\hline & CDK4i + siControl & $3.4 \pm 2.5$ & 0.35 & $70.6 \pm 5.4$ & $16.9 \pm 4.4$ & $9.1 \pm 1.5$ \\
\hline & CDK4i + siATG5 & $23.4 \pm 4.3$ & $<0.01$ & $50.6 \pm 4.1$ & $18.6 \pm 2.2$ & $7.4 \pm 2.4$ \\
\hline & CDK4i + siBECN 1 & $22.5 \pm 4.0$ & $<0.01$ & $51.4 \pm 3.1$ & $17.7 \pm 2.0$ & $8.5 \pm 3.0$ \\
\hline \multicolumn{7}{|l|}{ AIC (-) } \\
\hline \multirow[t]{6}{*}{ MCF7 } & DMSO + siControl & $2.6 \pm 0.7$ & - & $61.9 \pm 1.6$ & $28.8 \pm 1.6$ & $6.7 \pm 0.9$ \\
\hline & $\mathrm{DMSO}+\mathrm{si} A T G 5$ & $4.6 \pm 0.6$ & - & $56.2 \pm 1.8$ & $29.1 \pm 2.9$ & $10.1 \pm 2.2$ \\
\hline & $\mathrm{DMSO}+\mathrm{si} B E C N 1$ & $4.6 \pm 1.3$ & - & $55.1 \pm 1.7$ & $32.0 \pm 3.3$ & $8.3 \pm 2.0$ \\
\hline & CDK4i + siControl & $2.0 \pm 0.8$ & 0.37 & $72.6 \pm 2.8$ & $17.8 \pm 4.7$ & $7.6 \pm 2.4$ \\
\hline & CDK4i + siATG5 & $2.3 \pm 1.0$ & 0.06 & $67.1 \pm 2.0$ & $21.1 \pm 2.2$ & $9.5 \pm 4.4$ \\
\hline & $\mathrm{CDK} 4 \mathrm{i}+\mathrm{si} B E C N 1$ & $2.5 \pm 1.0$ & 0.07 & $66.8 \pm 4.9$ & $21.2 \pm 4.1$ & $9.5 \pm 5.4$ \\
\hline \multirow[t]{6}{*}{ KMST-6 } & DMSO + siControl & $1.0 \pm 0.4$ & - & $62.2 \pm 2.5$ & $29.2 \pm 2.9$ & $7.6 \pm 1.6$ \\
\hline & DMSO + siATG5 & $1.1 \pm 0.5$ & - & $60.7 \pm 3.4$ & $29.9 \pm 2.4$ & $8.3 \pm 1.8$ \\
\hline & $\mathrm{DMSO}+\mathrm{si} B E C N 1$ & $1.1 \pm 0.4$ & - & $61.0 \pm 4.3$ & $28.6 \pm 6.3$ & $9.3 \pm 3.6$ \\
\hline & CDK4i + siControl & $0.9 \pm 0.2$ & 0.34 & $76.1 \pm 2.4$ & $14.6 \pm 2.0$ & $8.4 \pm 0.3$ \\
\hline & CDK4i + siATG5 & $2.9 \pm 1.2$ & 0.06 & $73.3 \pm 2.0$ & $14.6 \pm 3.0$ & $9.2 \pm 5.3$ \\
\hline & $\mathrm{CDK} 4 \mathrm{i}+\mathrm{si} B E C N 1$ & $3.8 \pm 2.9$ & 0.12 & $73.5 \pm 3.7$ & $13.8 \pm 1.6$ & $8.9 \pm 4.2$ \\
\hline
\end{tabular}

Data are expressed as mean \pm SD. AIC, autophagy induced by CDK4 inhibitor; DMSO, dimethyl sulfoxide; CDK4i, CDK4 inhibitor. Sub-G ${ }_{1}$ fraction was examined paired t-test, between DMSO + siControl and CDK4i + siControl, between DMSO + siATG5 and CDK4i + siATG5, and between DMSO + siBECN1 and CDK4i + siBECN1. 


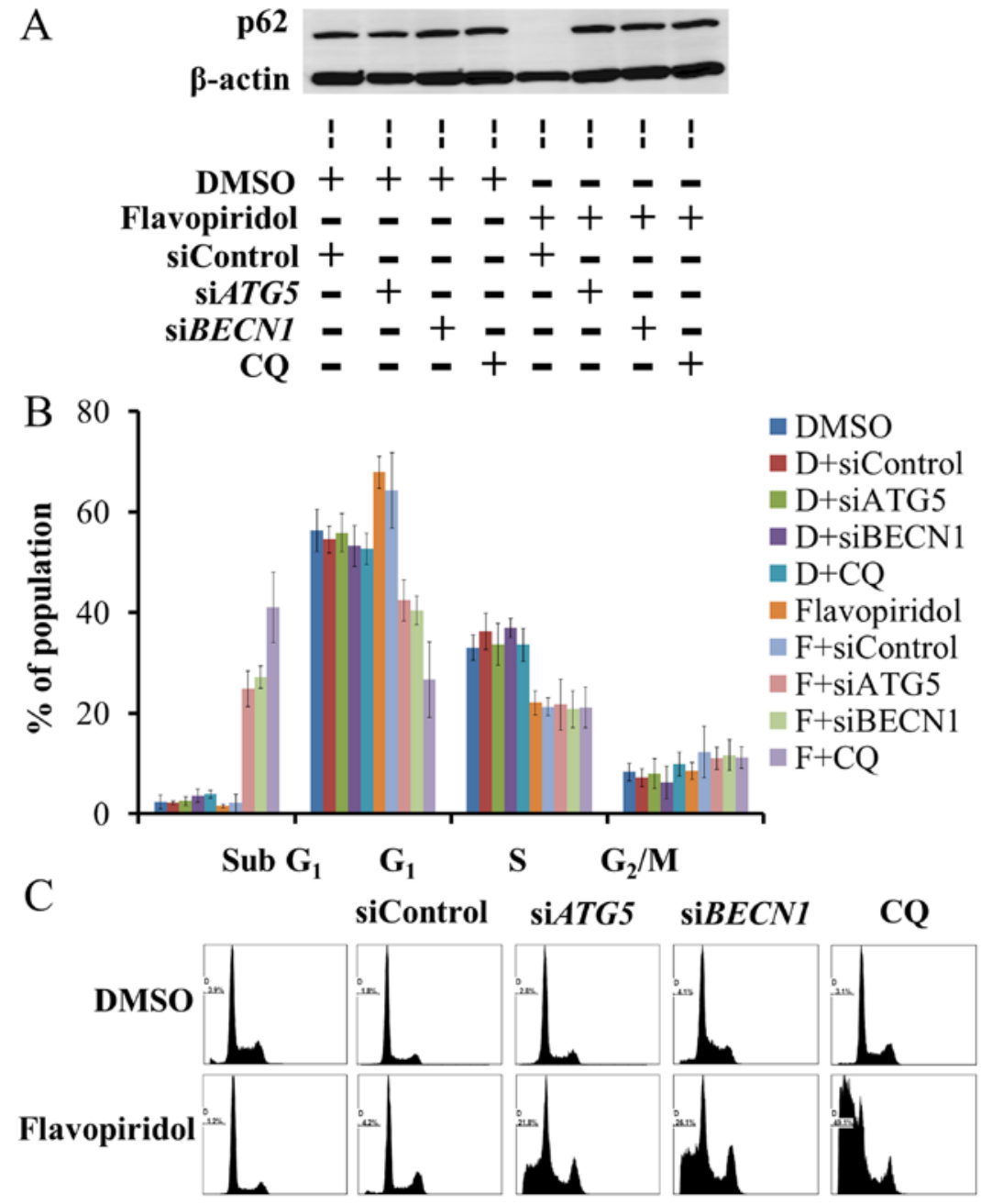

Figure 7. Cell cycle analysis for the combination of flavopiridol and autophagy inhibition in MDA-MB435S cell line. (A) Western blot analysis of p62 was performed following treatment with flavopiridol, instead of CDK4 inhibitor and autophagy inhibition, under the same conditions as described in Fig. 6. (B) Cell cycle analysis under the conditions as described for (A). The $\mathrm{x}$-axis indicates the phase of the cell cycle. The $\mathrm{y}$-axis indicates the proportion of the cell population. Values shown are mean \pm SD (n=3). D, DMSO; F, flavopiridol. (C) Images of flow cytometry under the conditions as in (B).

cells relative to the baseline. It seems that a concentration of CQ sufficient to induce autophagy is cytotoxic to NCI-N87. These results indicate that autophagy induced by small-molecule CKIs promoted cancer cell survival in the same manner as other anticancer therapies.

Since autophagy is a survival pathway for cancer cells, its inhibition has been considered to be a novel target for cancer treatment $(9,18,19-21)$. Although no small-molecule autophagy inhibitors have been developed to date, a number of experiments in cells and animal models have investigated the effects of the anti-malarial agents CQ and hydroxychloroquine (HCQ), which block the degradation of autophagy products by inhibiting lysosomal function $(9,20)$. Currently, the inhibition of autophagy is thought to contribute to cell death by mechanisms such as stress augmentation (22) and potentiation of DNA damage $(23,24)$. The use of an autophagy inhibitor with a genotoxic drug, which includes the majority of cytotoxic agents, might have potential as a novel combination anti-cancer therapy. In addition, the use of an autophagy inhibitor and an inhibitor targeting the PI3K/ AKT pathway, such as mTOR, PI3K, and AKT inhibitors, has also been reported as a potentially useful combination in preclinical models $(10,22-24)$, as well as clinical trials $(9,20)$. In this study, we demonstrated that small-molecule CKIs have the ability to induce autophagy and to induce apoptosis in five out of eight cancer cell lines, when combined with autophagy inhibition (CQ or knockdown of ATG5 or BECN1). These findings suggest that the combination therapy with flavopiridol or palbociclib and an autophagy inhibitor such as $\mathrm{CQ} / \mathrm{HCQ}$ could be a novel antitumor therapy because all have already been tested individually in humans.

If autophagy inhibition is to become a novel target for cancer treatment, then questions arise as to what kind of stress should be combined and which types of cancer are sensitive to autophagy inhibition. According to the Sanger COSMIC Database and our previous study (25), we did not find an association between AIC status and p53, Rb1, and BECN1 mutations (Table VII). HER2 overexpression and cyclin D1 amplification also seem to have no relationship with AIC status. However, previous studies have suggested that certain cancers are susceptible to autophagy inhibition $(10,26)$. For example, cancer cells with activation of the KRAS oncogenic signaling pathway exhibit high basal autophagy without any additional stress and are intolerant of other stresses. 
Table VII. The characteristics of cell lines used in this study.

\begin{tabular}{|c|c|c|c|c|c|c|}
\hline Cell line & Origin & p53 & $R b l$ & BECN1 & $\begin{array}{c}\text { HER2 } \\
\text { overexpression }\end{array}$ & $\begin{array}{c}\text { Cyclin D1 } \\
\text { amplification }\end{array}$ \\
\hline \multicolumn{7}{|l|}{$\mathrm{AIC}(+)$} \\
\hline BT474 & Breast & Mut & $\mathrm{LOH}$ & $\mathrm{LOH}$ & $(+)$ & $(+)$ \\
\hline MDA-MB435S & Breast & Mut & $\mathrm{LOH}$ & $\mathrm{LOH}$ & $(+)$ & $(-)$ \\
\hline SKBr3 & Breast & Mut & Normal & Normal & $(+)$ & $(-)$ \\
\hline A431 & Epidermis & Mut & $\mathrm{LOH}$ & Normal & ND & $(+)$ \\
\hline SW480 & Colon & Mut & Normal & Normal & ND & $(+)$ \\
\hline \multicolumn{7}{|l|}{ AIC (-) } \\
\hline MCF7 & Breast & wt & $\mathrm{LOH}$ & $\mathrm{LOH}$ & $(-)$ & $(+)$ \\
\hline MDA-MB231 & Breast & Mut & $\mathrm{LOH}$ & $\mathrm{LOH}$ & $(-)$ & $(+)$ \\
\hline NCI-N87 & Stomach & Mut & Normal & Normal & $(+)$ & $(-)$ \\
\hline KMST-6 & Fibroblast & wt & Normal & Normal & ND & $(-)$ \\
\hline
\end{tabular}

AIC, autophagy induced by CDK4 inhibitor; Mut, mutant type; wt, wild-type; LOH, loss of heterozygosity; ND, not determined.

The precise molecular mechanisms of autophagy induction by small-molecule CKIs also remain to be elucidated. Orvedahl et al reported on the molecules required for autophagy induced by viral infection by performing a comprehensive analysis using an shRNA library (27). Such high-throughput screening would be useful for detecting the relevant molecules associated with small-molecule CKI-induced autophagy. Once a molecule required for the autophagy induced by small-molecule CKIs is identified, a biomarker predicting the effectiveness of the combination of a small-molecule CKI and an autophagy inhibitor can be developed. At present, the degradation of p62 can act as a surrogate marker to predict subtypes susceptible to synthetic lethal interaction.

In conclusion, the combination of a small-molecule CKI and autophagy inhibition led to a synthetic lethal interaction and induced apoptosis in human solid cancer cell lines susceptible to the autophagy induced by small-molecule CKIs.

\section{Acknowledgements}

We would like to thank Eri Yokota, Satoko Aoki, and Hiromi Nakano for their technical assistance. We would also like to thank Enago for the English language review. C.I.received lecture fees from Taiho Pharmaceutical and Tokyo Clinical Oncology Group and research funding from Taiho Pharmaceutical, Chugai Pharmaceutical, Ono Pharmaceutical, Daiichi Sankyo Pharmaceutical, Takeda Pharmaceutical, and Yakult Pharmaceutical.

\section{References}

1. Golias $\mathrm{CH}$, Charalabopoulos A and Charalabopoulos K: Cell proliferation and cell cycle control: A mini review. Int J Clin Pract 58: 1134-1141, 2004.

2. Molinari M: Cell cycle checkpoints and their inactivation in human cancer. Cell Prolif 33: 261-274, 2000.

3. Lin TS, Ruppert AS, Johnson AJ, Fischer B, Heerema NA, Andritsos LA, Blum KA, Flynn JM, Jones JA, Hu W, et al: Phase II study of flavopiridol in relapsed chronic lymphocytic leukemia demonstrating high response rates in genetically high-risk disease. J Clin Oncol 27: 6012-6018, 2009.
4. Cristofanilli M, Turner NC, Bondarenko I, Ro J, Im SA, Masuda N, Colleoni M, DeMichele A, Loi S, Verma S, et al: Fulvestrant plus palbociclib versus fulvestrant plus placebo for treatment of hormone-receptor-positive,HER2-negative metastatic breast cancer that progressed on previous endocrine therapy (PALOMA-3): Final analysis of the multicentre, double-blind, phase 3 randomised controlled trial. Lancet Oncol 17: 425-439, 2016.

5. Liang J, Shao SH, Xu ZX, Hennessy B, Ding Z, Larrea M, Kondo S, Dumont DJ, Gutterman JU, Walker CL, et al: The energy sensing LKB1-AMPK pathway regulates p27(kip1) phosphorylation mediating the decision to enter autophagy or apoptosis. Nat Cell Biol 9: 218-224, 2007.

6. Fujiwara K, Daido S, Yamamoto A, Kobayashi R, Yokoyama T, Aoki H, Iwado E, Shinojima N, Kondo Y and Kondo S: Pivotal role of the cyclin-dependent kinase inhibitor p21WAF1/CIP1 in apoptosis and autophagy. J Biol Chem 283: 388-397, 2008.

7. Jiang H, Martin V, Gomez-Manzano C, Johnson DG, Alonso M, White E, Xu J, McDonnell TJ, Shinojima N and Fueyo J: The RB-E2F1 pathway regulates autophagy. Cancer Res 70: 7882-7893, 2010

8. Levine B and Klionsky DJ: Development by self-digestion: Molecular mechanisms and biological functions of autophagy. Dev Cell 6: 463-477, 2004.

9. White E and DiPaola RS: The double-edged sword of autophagy modulation in cancer. Clin Cancer Res 15: 5308-5316, 2009.

10. Yang S, Wang X, Contino G, Liesa M, Sahin E, Ying H, Bause A, Li Y, Stommel JM, Dell'antonio G, et al: Pancreatic cancers require autophagy for tumor growth. Genes Dev 25: 717-729, 2011.

11. Yang ZJ, Chee CE, Huang S and Sinicrope F: Autophagy modulation for cancer therapy. Cancer Biol Ther 11: 169-176, 2011.

12. Kakudo Y, Shibata H, Otsuka K, Kato S and Ishioka C: Lack of correlation between p53-dependent transcriptional activity and the ability to induce apoptosis among 179 mutant p53s. Cancer Res 65: 2108-2114, 2005.

13. Sakamoto Y, Kato S, Takahashi M, Okada Y, Yasuda K, Watanabe G, Imai H, Sato A and Ishioka C: Contribution of autophagic cell death to p53-dependent cell death in human glioblastoma cell line SF126. Cancer Sci 102: 799-807, 2011.

14. Watanabe $\mathrm{G}$, Kato $\mathrm{S}$, Nakata $\mathrm{H}$, Ishida T, Ohuchi $\mathrm{N}$ and Ishioka C: alphaB-crystallin: A novel p53-target gene required for p53-dependent apoptosis. Cancer Sci 100: 2368-2375, 2009.

15. Foster DA, Yellen P, Xu L and Saqcena M: Regulation of G1 cell cycle progression: Distinguishing the restriction point from a nutrient-sensing cell growth checkpoint(s). Genes Cancer 1: 1124-1131, 2010.

16. Chen $\mathrm{N}$ and Karantza-Wadsworth V: Role and regulation of autophagy in cancer. Biochim Biophys Acta 1793: 1516-1523, 2009.

17. Apel A, Herr I, Schwarz H, Rodemann HP and Mayer A: Blocked autophagy sensitizes resistant carcinoma cells to radiation therapy. Cancer Res 68: 1485-1494, 2008. 
18. Cook KL, Shajahan AN and Clarke R: Autophagy and endocrine resistance in breast cancer. Expert Rev Anticancer Ther 11: 1283-1294, 2011.

19. Mathew R, Karantza-Wadsworth V and White E: Role of autophagy in cancer. Nat Rev Cancer 7: 961-967, 2007.

20. Amaravadi RK, Lippincott-Schwartz J, Yin XM, Weiss WA, Takebe N, Timmer W, DiPaola RS, Lotze MT and White E: Principles and current strategies for targeting autophagy for cancer treatment. Clin Cancer Res 17: 654-666, 2011.

21. Garber K: Inducing indigestion: Companies embrace autophagy inhibitors. J Natl Cancer Inst 103: 708-710, 2011.

22. Sheen JH, Zoncu R, Kim D and Sabatini DM: Defective regulation of autophagy upon leucine deprivation reveals a targetable liability of human melanoma cells in vitro and in vivo. Cancer Cell 19: 613-628, 2011.

23. Karantza-Wadsworth V, Patel S, Kravchuk O, Chen G, Mathew R Jin $S$ and White E: Autophagy mitigates metabolic stress and genome damage in mammary tumorigenesis. Genes Dev 21: 1621-1635, 2007.
24. Mathew R, Kongara S, Beaudoin B, Karp CM, Bray K, Degenhardt K, Chen G, Jin S and White E: Autophagy suppresses tumor progression by limiting chromosomal instability. Genes Dev 21: 1367-1381, 2007.

25. Soussi T, Kato S, Levy PP and Ishioka C: Reassessment of the TP53 mutation database in human disease by data mining with a library of TP53 missense mutations. Hum Mutat 25: 6-17, 2005.

26. Bae H and Guan JL: Suppression of autophagy by FIP200 deletion impairs DNA damage repair and increases cell death upon treatments with anticancer agents. Mol Cancer Res 9: 1232-1241, 2011.

27. Orvedahl A, Sumpter R Jr, Xiao G, Ng A, Zou Z, Tang Y, Narimatsu M, Gilpin C, Sun Q, Roth M, et al: Image-based genome-wide siRNA screen identifies selective autophagy factors. Nature 480: 113-117, 2011. 